\title{
Vineyards, but not cities, are associated with lower presence of a generalist bird, the Common Blackbird (Turdus merula), in Western France
}

\author{
Bertille Mohring ${ }^{1,2^{*}}$ (D) François Brischoux ${ }^{1}$ and Frédéric Angelier ${ }^{1}$
}

\begin{abstract}
Background: Land-use change is one of the main drivers of the global erosion of biodiversity. In that context, it is crucial to understand how landscape characteristics drive the presence of rare endangered species. Nevertheless, it is also important to study common species in multiple habitats, because they represent a large proportion of biodiversity and are essential to maintain ecological functions. Interestingly, some habitats, as farmlands with permanent crops (e.g. vineyards), have been overlooked in the literature.
\end{abstract}

Methods: In this study, we investigated the distribution of a widespread and common bird species, the Common Blackbird (Turdus merula), within and between the three main habitats of our study area (rural Western France). We specifically focused on (1) woodlands, (2) farmlands with a high vineyard coverage, and (3) moderately urbanized areas. Specifically, we aimed to assess the beneficial and detrimental effects of these habitats and their fine-scale composition on the presence of a common bird species, relying on a survey by point counts (nearly 100 locations). We studied the effects of habitats and gradients of fine-scale habitat composition on blackbird presence using logistic regression analyses.

Results: Blackbirds were present in all studied habitats. However, their presence varied between habitats, being lower in vineyards than in woodlands and cities. In woodlands and cities, fine-scale analyses did not reveal any component driving the species' presence. However, we found that shrub and tree vegetation cover had a significant positive effect on blackbird presence in vineyards.

Conclusions: Our results are in agreement with the definition of a generalist species. Interestingly, species distribution varied between habitats. The high presence of blackbirds in urban areas suggests that medium-sized cities, despite their artificialization, do not constrain the settlement of this former forest specialist and that green spaces may allow blackbirds to thrive in medium-sized cities. On the contrary, we found an impoverished presence of blackbirds in vineyards and a positive effect of vegetation on their presence in these landscapes. This suggests that permanent crops, and more generally farmlands, may impose important constraints to common species. Future studies should examine how to enhance biodiversity through agricultural management policies, especially in vineyards.

Keywords: Agriculture, Biodiversity, Birds, Forest, Turdus merula, Urbanization, Vineyards

*Correspondence: bertille.mohring@abo.fi

${ }^{1}$ Centre d'Etudes Biologiques de Chizé, UMR 7372, CNRS - La Rochelle Université, 79360 Villiers en Bois, France

Full list of author information is available at the end of the article

\section{Background}

Landscape characteristics such as structure or composition are known to affect biodiversity (Devictor et al. 2008). Indeed, land-use change (i.e. modification, 
fragmentation or destruction of natural habitats) is known to be one of the main drivers of biodiversity loss (Donald et al. 2001; Baillie et al. 2004; Foley et al. 2005; Newbold et al. 2016; Stanton et al. 2018; Paquet et al. 2019). In the current global context of increased human pressure on lands, it is especially relevant to investigate the effects of landscape characteristics on wild species' diversity and abundance.

Among wildlife, species can be split into two main categories in relation to their dependence on ecosystem characteristics. Generalist species have a broader environmental tolerance and are able to exploit a wider ecological niche than specialist species (Futuyma and Moreno 1988; Mac Nally 1989; Kassen 2002; Julliard et al. 2006; Reif et al. 2007). Thus, specialist species are highly dependent on specific environmental characteristics, and, consequently, are often less able to cope with habitat change than generalist species (Brouat et al. 2004; Wretenberg et al. 2006; Devictor et al. 2008; Carrara et al. 2015).

While many specialist bird species have been declining over the past decades (Siriwardena et al. 1998; Gregory et al. 2004; Shultz et al. 2005; Wretenberg et al. 2006), generalist species have mainly remained stable or have increased (Siriwardena et al. 1998; Reif et al. 2007). Overall, they are replacing specialist species, leading to a homogenisation of biodiversity and a loss of specific ecological niches (Olden 2006; Clavel et al. 2011). The current decline of specialist species and its link with habitat modifications have been widely studied (Gregory et al. 2004; Shultz et al. 2005; Wretenberg et al. 2006), and conservation and management policies mainly focus on biodiversity loss by studying population trends of iconic specialist species (Hobday et al. 2015). However, while it is important to understand how changes in landscape characteristics can affect rare species, that are threatened with extinction, there is also growing evidence that maintaining ordinary biodiversity, often made of common generalist species, is equally essential to preserve ecological functions and biodiversity (Gaston and Fuller 2008; Godet 2010; Lennon et al. 2011; Brédif and Simon 2014).

Among generalist bird species, the widespread Common Blackbird (Turdus merula) is especially relevant to study this topic. Formerly a forest specialist species, the Common Blackbird began to expand and colonize new artificial habitats, especially urban ecosystems, at the beginning of the 19th century (Luniak 2004). It can now be found in a large diversity of habitats and is considered as a generalist and ubiquitous species (Buckley 1995; Hatchwell et al. 1996). However, the extent of the beneficial or detrimental effects of habitat composition and structure on the distribution of such generalist species remains unknown.
In this study, we investigated (1) Common Blackbird presence across the three main terrestrial habitats (woodland, farmland and urban habitats; Ellis and Ramankutty 2008). Importantly, we focused on an intensive agricultural system dominated by permanent crops. While nonpermanent crops have been widely studied, little is known about biodiversity in permanent agricultural systems such as vineyards (Assandri et al. 2017a). In addition, for each habitat, we explored if (2) the presence of blackbirds varied along fine-scale gradients of habitat composition. As a generalist species, we expect that (1) blackbirds will be present in the three studied habitats. We specifically predict that (2) the presence of this generalist species should not be dramatically reduced in urban and agricultural landscapes compared to woodlands, except when the degree of habitat artificialization and alteration is intense (i.e. highly urbanized sites and intensive agricultural sites). Moreover and accordingly, we also predict that (3) vegetation cover will drive the distribution of Common Blackbirds in all habitats because this generalist species relies mainly on shrubs, trees and soil invertebrates for feeding and nesting (Davis 1966; Sierro and Arlettaz 2003; Guittet et al. 2011; Assandri et al. 2017b).

\section{Methods}

\section{Common Blackbird census}

In the spring 2019, between March 28th and April 9th, we carried out a Common Blackbird survey using 5-min point counts at the beginning of the breeding season in three habitats differing in their degree of artificialization and alteration (woodland, farmland and urban habitats). The census period was chosen according to Common Blackbird breeding phenology, in order to allow an accurate detectability of breeding individuals of this precocial bird species (Najmanová and Adamík 2009; Jankowiak et al. 2014). Overall, 93 census sites were monitored and these sites were homogeneously distributed between habitats ( 31 census sites per habitat). Visits to census sites that belonged to the same type of habitat were spread over the study period to avoid any bias due to changes in bird detectability during the breeding period.

The Common Blackbird census protocol was adapted from the French Breeding Bird Survey (BBS) protocol (Julliard and Jiguet 2002). The survey was carried out between one and four hours after sunrise to avoid higher activity, and thus increased detectability of birds, during the dawn chorus and lower activity, and thus decreased detectability, in the late morning (Ralph et al. 1995). During $5 \mathrm{~min}$, the observer stayed motionless at the census site and looked for Common Blackbirds. The observer spent the first minute looking for Common Blackbirds (by hear or sight) and then broadcasted a 4-min playback to improve bird detectability (Dabelsteen 1982, 1984; 
Ralph et al. 1995; Kubel and Yahner 2007). The playback consisted in alternating 30-s phases of silence and a mix of different Common Blackbird songs and calls, imitating a natural vocal behaviour of the species (Dabelsteen and Pedersen 1990; Dabelsteen 1992). As male Common Blackbirds are highly territorial and respond more to playback than females (Diehl and Helb 1986), females were not included in Common Blackbird counts (females were detected in two monitored sites only). Thus, the number of male Common Blackbird (seen or heard) was counted for each census site. However, as detecting more than one male Common Blackbird was a rare event (two birds detected at the same census site at most, only seven sites with more than one male), bird abundance was converted to presence or absence for each census site (1 if presence was detected, 0 if presence was not detected).

\section{Site selection and characterization}

This survey was conducted on three populations of Common Blackbirds in the northern part of the Nouvelle Aquitaine region (Western France; Fig. 1). Three sample zones were selected according to their habitat type: woodland $\left(46^{\circ} 08^{\prime} \mathrm{N}, 0^{\circ} 23^{\prime} \mathrm{W}\right)$, farmland $\left(45^{\circ} 47^{\prime} \mathrm{N}\right.$, $\left.0^{\circ} 25^{\prime} \mathrm{W}\right)$ and urban $\left(46^{\circ} 18^{\prime} \mathrm{N}, 0^{\circ} 28^{\prime} \mathrm{W}\right)$ habitats. Sample zones in woodland and farmland habitat both covered $150 \mathrm{~km}^{2}$ while urban sample zone covered $35 \mathrm{~km}^{2}$, due to the medium size of the studied city. The woodlands were characterized by temperate broadleaf and mixed forest $(87 \%$ of deciduous trees mainly composed of Oak (Quercus spp.) and Beech (Fagus sylvatica) and 13\% of resinous trees mainly composed of Black Pines (Pinus nigra)). The studied agricultural landscape was located in the Cognac region and was characterized by the high presence of permanent crops, i.e. vineyards (Cognac vineyard). More precisely, this rural habitat consists of patches of villages, small woods and intensive agricultural areas surrounded by hedges. Agricultural areas are mainly permanent crops like vineyards, but non-permanent crops such as cereal crops and grasslands can also be found in that area. The studied urban habitat was the medium size city of Niort ( 60,000 inhabitants). This typical French city is characterized by built-up areas and

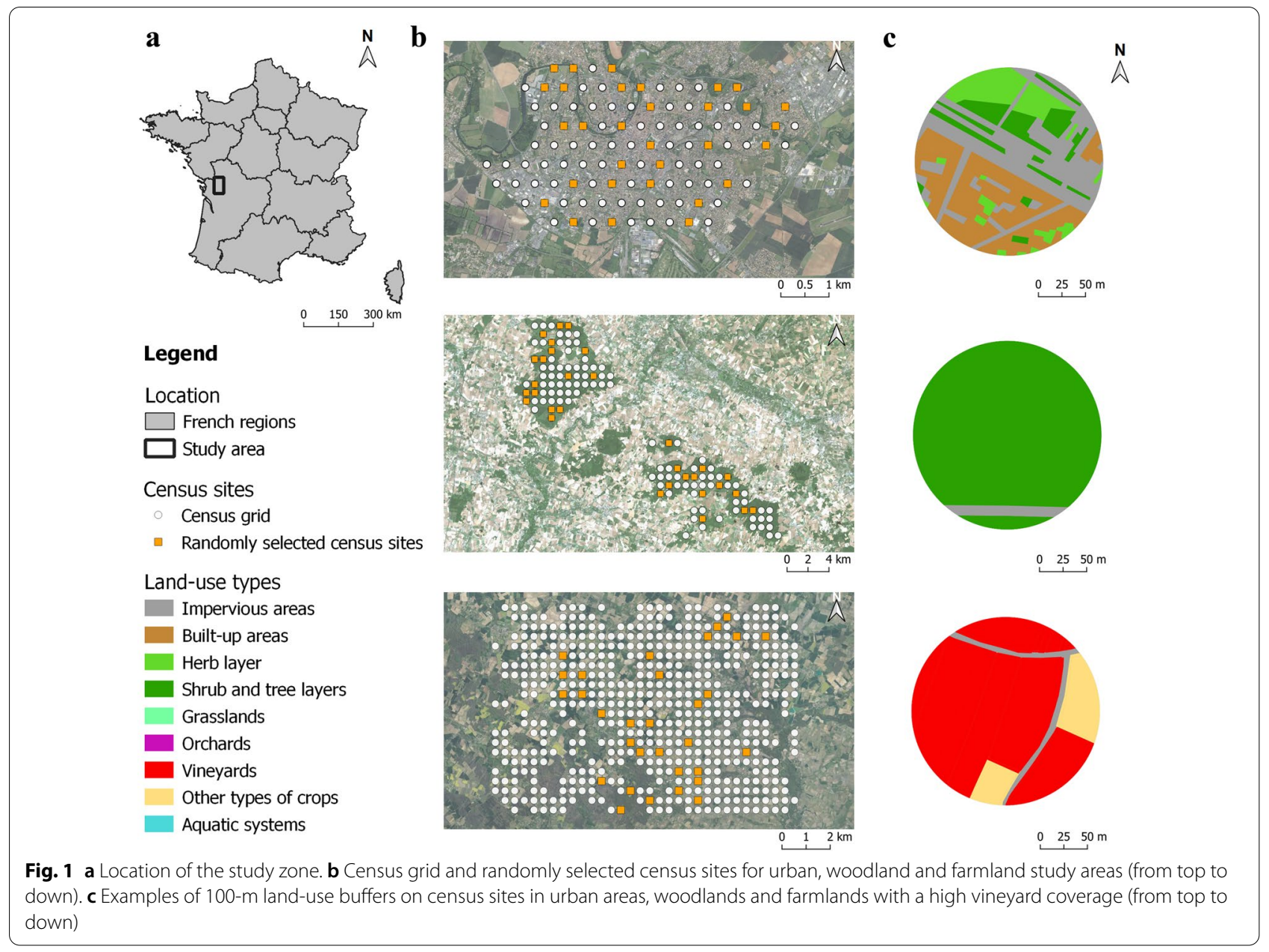


numerous urban green areas. It is crossed by the Sèvre Niortaise River and surrounded by agricultural plains and woodlands.

In each zone, sites were randomly selected from a grid. Grid cell size was smaller in urban census sites $(400 \mathrm{~m}$ wide) compared to farmland and woodland sites $(800 \mathrm{~m}$ wide) as cities are known to be highly fragmented and heterogeneous landscapes (Luck and Smallbone 2010). In each site of the grid, habitat composition was characterized within a $100 \mathrm{~m}$-radius buffer around each census site (Fig. 1). The size of the buffer was selected according to available estimates of breeding blackbird daily home ranges (Snow 1956; Fritsch et al. 2012). We relied on the French national geographic institute (IGN) topographic database BDTopo ${ }^{\circledR}$ to characterize urban and forest areas. We also used the French land parcel identification system to characterize agricultural landscapes. Habitat composition was divided into nine categories: (1) impervious areas; (2) built-up areas; (3) herb layer; (4) shrub and tree layers; (5) grasslands; (6) orchards; (7) vineyards; (8) other types of crops and (9) aquatic systems. Orchards and vineyards were separated from other types of crops as they covered a large part of our study area. Sites that belonged to the study zone but did not correspond to the required habitat type were removed. In woodlands, only forest sites (i.e. sites covered by at least $60 \%$ of shrubs and trees) were kept for further selection and locations at the limit of forests were removed to prevent edge effects as blackbirds show a preference for nesting in forest edges (Hinsley et al. 1995). In farmland areas, rural sites without any field were removed. In urban habitats, sites at the edge of the city were removed. After removal of census sites that did not correspond to the aforementioned criteria, 31 census sites were randomly selected in each habitat for a total of 93 sites.

\section{Statistical data analyses Variation in blackbird presence in the three main habitats}

All statistical analyses were conducted with $R$ ( $R$ version 3.6.1; R Core Team 2019). We implemented a logistic regression model with Common Blackbird presence as the dependent variable and habitat type as the qualitative explanatory variable. Time since sunrise and the interaction between habitat and time since sunrise were added to the model to account for the potential variation in detection over time due to changes in bird activity. We relied on information criterion corrected for small sample size (AICc) to identify the most parsimonious model explaining variations in Common Blackbird presence across habitats (i.e. model with the lowest AICc; Burnham and Anderson 2002; Barton 2020) from all possible combinations of explanatory variables (models built using 'dredge' function, MuMIn package; Barton 2020).

\section{Variation in blackbird presence along fine-scale habitat gradients}

After studying the variation in Common Blackbird presence across habitats, we investigated the fine-scale variation in distribution of the species by focusing on landscape characteristics in each census site. Because some explanatory fine-scale habitat variables co-varied, we ran principal components analyses (PCA built with the 'PCA' function, FactoMineR package; Lê et al. 2008; all variables included in PCA were centered and scaled) for each habitat type to circumvent collinearity issues and describe census sites using gradients of habitat.

The first principal component $\left(\mathrm{PC}_{1 \mathrm{~W}}\right)$ of the PCA run on woodland census sites $\left(\mathrm{PCA}_{\mathrm{W}}\right)$ explained $40.56 \%$ of the variation between sites. Decreasing $\mathrm{PC}_{1 \mathrm{~W}}$ values were associated with an increasing shrub and tree cover (Pearson correlation: $r=-0.98, P<0.01)$, and a decreasing coverage of other types of land-use (impervious areas, water, grasslands, orchards and other types of crops, all $P<0.01)$. The second principal component $\left(\mathrm{PC}_{2 \mathrm{~W}}\right)$ explained $29.04 \%$ of the variation between woodland census sites. Increasing values of $\mathrm{PC}_{2 \mathrm{~W}}$ were associated with an increasing field coverage in the census sites (grassland and other crops correlations: all $r>0.82$, all $P<0.05$ ).

The first principal component $\left(\mathrm{PC}_{1 \mathrm{~F}}\right)$ of the $\mathrm{PCA}$ run on farmland census sites $\left(\mathrm{PCA}_{\mathrm{F}}\right)$ explained $30.48 \%$ of landscape variation between sites. Increasing $\mathrm{PC}_{1 \mathrm{~F}}$ values were associated with increasing urbanization and water coverage (built-up areas, impervious areas and water correlations: all $r>0.86$, all $P<0.01)$. The second principal component $\left(\mathrm{PC}_{2 \mathrm{~F}}\right)$ explained $23.01 \%$ of the variation between farmland census sites. Decreasing values of $\mathrm{PC}_{2 \mathrm{~F}}$ were associated with an increasing coverage in permanent crops: vineyards (correlation: $r=-0.94, P<0.01$ ), low vegetation (herb layer correlation: $r=-0.39, P<0.05$ ), a decreasing coverage in other types of farmlands (other crops and grassland correlations: all $r>0.49$, all $P<0.01$ ), and shrub and tree layer (correlation: $r=0.42, P<0.05$ ).

The first principal component $\left(\mathrm{PC}_{1 \mathrm{U}}\right)$ of the $\mathrm{PCA}$ run on urban census sites $\left(\mathrm{PCA}_{U}\right)$ explained $35.17 \%$ of landscape variations between sites. Increasing $\mathrm{PC}_{1 \mathrm{U}}$ values were associated with a decreasing urban coverage (built-up and impervious area correlations: all $r<-0.72$, all $P<0.01$ ), and an increasing field and water coverage (correlations: all $r>0.55$, all $P<0.01$ ). Thus, $\mathrm{PC}_{1 \mathrm{U}}$ corresponded to a decreasing gradient of urbanization in the urban habitat. The second principal component $\left(\mathrm{PC}_{2 \mathrm{U}}\right)$ explained $22.92 \%$ of the variation between urban sites. $\mathrm{PC}_{2 \mathrm{U}}$ described a vegetation gradient, with increasing values of $\mathrm{PC}_{2 \mathrm{U}}$ being associated with an increasing cover in all natural vegetation layers (herb, shrub and tree layer correlations: all $r>0.65$, all $P<0.01)$, and a decreasing grassland coverage (correlation: $r=-0.42, P<0.01$ ). 
We then used logistic regression models with Common Blackbird presence as the dependent variable and the values associated with each site on PCA axis as well as the time since sunrise as quantitative explanatory variables. Models were built by using all possible combinations of explanatory variables (principal components and time after sunrise, and model selection was performed by using the 'dredge' function, MuMIn package; Barton 2020). As for the analysis of variation in blackbird presence between habitats, the most parsimonious model explaining variations in blackbird presence within habitats was selected according to AICc values (Burnham and Anderson 2002). As not taking into account the presence of neighbouring conspecifics may induce overestimation of the effects of landscape components on Common Blackbird presence, by confounding space and habitat effects (Betts et al. 2006), we looked for spatial dependency in Common Blackbird presence. Thus, for each selected model, we checked for spatial autocorrelation in Pearson residuals of logistic regression models, using Moran's $I$ test (computed with 'moran.test' function, spdep package; Bivand and Wong 2018). Additionally, as PCA principal components did not explain all variance between census sites (between 53.49\% and 69.6\% of between-site variations explained by the two selected principal components), and as some dependent variables, such as shrub and tree vegetation cover, or vineyard cover, were expected to drive Common Blackbird presence, either positively (vegetation cover; Sierro and Arlettaz 2003; Steel et al. 2017), or negatively (vineyard cover; Pithon et al. 2016; Steel et al. 2017), we also tested for the additive effect of fine-scale habitat variables taken individually. Models were built by using all possible combinations of explanatory variables (landscape components and time after sunrise). As landscape variables co-varied, they were tested in separate models to circumvent collinearity issues. Model selection was performed by using the 'dredge' function (MuMIn package; Barton 2020).
Such analyses aimed at avoiding missing the significant response of Common Blackbirds to one of the individual habitat (Rotenberry and Wiens 1981).

\section{Results}

\section{Common Blackbird presence in the three main habitats}

The most parsimonious model (i.e. lowest AICc) explaining variations in Common Blackbird presence across habitats included habitat and time after sunrise as explanatory variables (Table 1). Common Blackbirds were not identically distributed in the three main habitats (GLM: $X^{2}=7.25, N=93, P=0.027$ ). Indeed, their presence was significantly higher in woodland $(Z=2.188$, $P=0.029)$ and urban habitats $(Z=2.357, P=0.018)$ than in vineyards (Fig. 2). Time after sunrise had a negative effect on Common Blackbird presence (GLM: $\chi^{2}=4.68$, $N=93, P=0.030$ ).

\section{Common Blackbird distribution along fine-scale gradients of habitat}

In woodland sites, the most parsimonious model was the null model (Table 2). Hence, neither the increasing forest gradient $\left(\mathrm{PC}_{1 \mathrm{~W}}\right)$ nor the increasing crop gradient $\left(\mathrm{PC}_{2 \mathrm{~W}}\right)$ had an effect on Common Blackbird presence $\left(\mathrm{PC}_{1 \mathrm{~W}}\right.$ and $\mathrm{PC}_{2 \mathrm{~W}}$ were not selected in the most parsimonious model). We did not find any significant autocorrelation in model residuals (Moran's $I=0.199, P=0.421$ ).

In urban sites, the model with the lowest AICc contained $\mathrm{PC}_{1 \mathrm{U}}$ as selected explanatory variable but it was only slightly better than the null model (Table 2). Also, the effect of the urbanization gradient $\left(\mathrm{PC}_{1 \mathrm{U}}\right)$ on Common Blackbird presence was not significant in this model $\left(\mathrm{PC}_{1 \mathrm{U}}: Z=1.416, N=31, P=0.157\right)$. The vegetation gradient $\left(\mathrm{PC}_{2 \mathrm{U}}\right)$ was not selected in the best model explaining Common Blackbird distribution along fine-scale gradients in urban sites. We did not find any significant autocorrelation in model residuals (Moran's $I=-0.152$, $P=0.560)$.

Table 1 Model selection establishing variations in Common Blackbird presence across the three studied habitats and taking into account the time since sunrise

\begin{tabular}{|c|c|c|c|c|c|c|}
\hline Models & Fixed parameters & $d f^{a}$ & $\mathrm{LL}^{\mathbf{b}}$ & $\mathrm{AICc}$ & $\triangle \mathrm{AICc}$ & $w_{i}^{c}$ \\
\hline$M_{1}$ & Habitat + Time & 4 & -58.924 & 126.3 & 0.00 & 0.581 \\
\hline$M_{2}$ & Habitat & 3 & -61.266 & 128.8 & 2.50 & 0.167 \\
\hline$M_{3}$ & Time & 2 & -62.551 & 129.2 & 2.93 & 0.134 \\
\hline $\mathrm{M}_{4}$ & Habitat + Time + Habitat $\times$ Time & 6 & -58.899 & 130.8 & 4.47 & 0.062 \\
\hline$M_{0}$ & Null model & 1 & -64.457 & 131.0 & 4.66 & 0.057 \\
\hline
\end{tabular}

Models are ranked according to decreasing statistical support, as indicated by AICc. Habitat: woodland, urban and farmland. Time since sunrise: Time. The most parsimonious model is in italics

a df indicates the degrees of freedom

b LL accounts for loglikelihood

c $w_{i}$ is the Akaike weight of the model. 


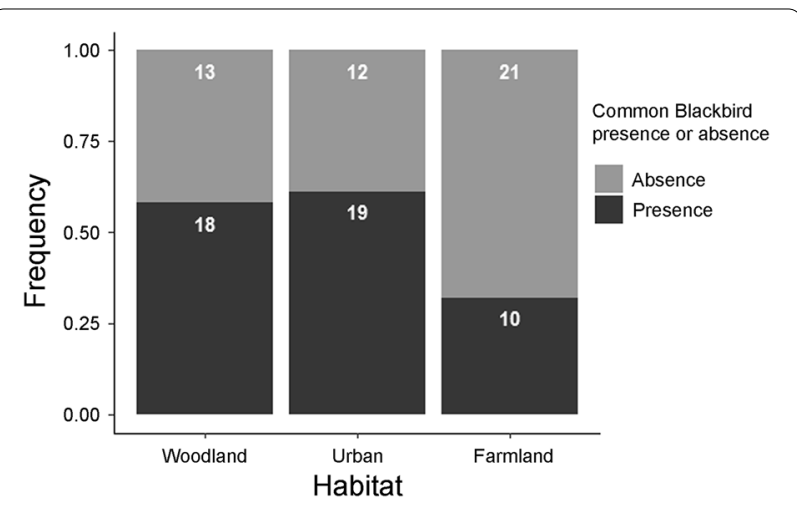

Fig. 2 Common Blackbird distribution in the three studied habitats. Total number of census sites in which Common Blackbirds were respectively present or absent are reported in bold white

In farmland sites, the most parsimonious model explaining Common Blackbird distribution was the null model (Table 2). Hence, urbanization and aquatic system coverage gradient $\left(\mathrm{PC}_{1 \mathrm{~F}}\right)$ were not selected to explain Common Blackbird presence. The effect of increasing coverage in vineyards and low vegetation and decreasing coverage in other types of farmlands $\left(\mathrm{PC}_{2 \mathrm{~F}}\right)$ on Common Blackbird were not selected either in the most supported model. We did not find any significant autocorrelation in model residuals (Moran's $I=-0.058, P=0.523$ ).
The time after sunrise did not significantly explain Common Blackbird presence neither in the three gradient fine-scale analyses (time after sunrise was not included in the most parsimonious models describing variations in Common Blackbird presence within habitats).

By testing separately the effect of landscape components on Common Blackbird presence in woodland and urban census sites, we did not evidence any significant effect of any of the studied landscape component (the null model had the lowest AICc value, Table 3). However, in farmland census sites, the model with the lowest AICc contained the percentage of shrub and tree vegetation cover, and time after sunrise as explanatory variables (Table 3 ). In this model, shrub and tree vegetation layer had a significant positive effect on Common Blackbird presence (estimates, Mean $\pm \mathrm{SE}$, $0.04 \pm 0.02, Z=2.018, P=0.044, N=31$; Fig. 3 ), while the effect of time after sunrise was not statistically significant despite a negative trend (estimates, Mean \pm SE, - 0.02 $\pm 0.01, Z=-1.794, P=0.073, N=31$ ). Importantly, the $\triangle \mathrm{AICc}$ between this model and the null model was lower than $2(\triangle \mathrm{AICc}=1.301)$, suggesting that they can both be supported by the data (Burnham and Anderson 2002).

Table 2 Model selection establishing variations in Common Blackbird presence in relation to fine-scale gradients of habitat and time since sunrise

\begin{tabular}{|c|c|c|c|c|c|c|}
\hline Model & Fixed parameters & df & LL & AICc & $\Delta \mathrm{AICC}$ & $w_{i}$ \\
\hline \multicolumn{7}{|c|}{ Woodland census sites } \\
\hline$M_{0}$ & Null model & 1 & -21.083 & 44.303 & 0 & 0.240 \\
\hline$M_{1}$ & Time & 2 & -19.979 & 44.386 & 0.083 & 0.230 \\
\hline $\mathrm{M}_{2}$ & $\mathrm{PC}_{1 \mathrm{~W}}+$ Time & 3 & -19.161 & 45.211 & 0.908 & 0.153 \\
\hline$M_{3}$ & $P C_{1 W}$ & 2 & -20.553 & 45.535 & 1.232 & 0.130 \\
\hline $\mathrm{M}_{4}$ & $\mathrm{PC}_{2 \mathrm{~W}}$ & 2 & -21.003 & 46.435 & 2.132 & 0.130 \\
\hline \multicolumn{7}{|c|}{ Urban census sites } \\
\hline$M_{1}$ & $P C_{1 U}$ & 2 & -19.526 & 43.480 & 0 & 0.241 \\
\hline$M_{0}$ & Null model & 1 & -20.690 & 43.519 & 0.039 & 0.236 \\
\hline $\mathrm{M}_{2}$ & Time & 2 & -20.001 & 44.430 & 0.951 & 0.150 \\
\hline$M_{3}$ & $\mathrm{PC}_{1 \mathrm{U}}+$ Time & 3 & -18.857 & 44.603 & 1.123 & 0.137 \\
\hline$M_{4}$ & $\mathrm{PC}_{2 \mathrm{U}}$ & 2 & -20.677 & 45.782 & 2.302 & 0.076 \\
\hline \multicolumn{7}{|c|}{ Farmland census sites } \\
\hline$M_{0}$ & Null model & 1 & -19.493 & 41.123 & 0 & 0.351 \\
\hline$M_{1}$ & Time & 2 & -18.919 & 42.267 & 1.144 & 0.198 \\
\hline$M_{2}$ & $\mathrm{PC}_{2 \mathrm{~F}}$ & 2 & -19.308 & 43.045 & 1.921 & 0.134 \\
\hline $\mathrm{M}_{3}$ & $P C_{1 F}$ & 2 & -19.469 & 43.367 & 2.244 & 0.114 \\
\hline$M_{4}$ & $\mathrm{PC}_{2 \mathrm{~F}}+$ Time & 3 & -18.563 & 44.015 & 2.891 & 0.083 \\
\hline
\end{tabular}

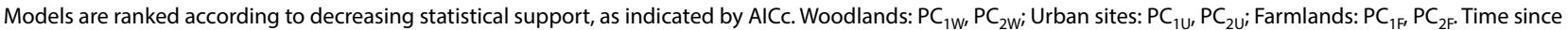
sunrise: Time. The five best models are shown 
Table 3 Model selection establishing variations in Common Blackbird presence in relation to fine-scale landscape components and time after sunrise

\begin{tabular}{|c|c|c|c|c|c|c|}
\hline Model & Fixed parameters & df & LL & AICc & $\triangle \mathrm{AICC}$ & $w_{i}$ \\
\hline \multicolumn{7}{|c|}{ Woodland census sites } \\
\hline$M_{0}$ & Null model & 1 & -21.083 & 44.303 & 0 & 0.257 \\
\hline$M_{1}$ & Time & 2 & -19.979 & 44.386 & 0.083 & 0.247 \\
\hline $\mathrm{M}_{2}$ & $\mathrm{P}_{\text {Trees }}+$ Time & 3 & -19.335 & 45.559 & 1.256 & 0.137 \\
\hline $\mathrm{M}_{3}$ & $\mathrm{P}_{\text {Impervious }}+$ Time & 3 & -19.405 & 45.698 & 1.395 & 0.128 \\
\hline $\mathrm{M}_{4}$ & $\mathrm{P}_{\text {Trees }}$ & 2 & -20.675 & 45.779 & 1.476 & 0.123 \\
\hline \multicolumn{7}{|c|}{ Urban census sites } \\
\hline$M_{0}$ & Null model & 1 & -20.690 & 43.519 & 0 & 0.101 \\
\hline$M_{1}$ & $P_{\text {Herb }}$ & 2 & -19.778 & 43.985 & 0.466 & 0.080 \\
\hline $\mathrm{M}_{2}$ & $P_{\text {Grasslands }}$ & 2 & -19.784 & 43.997 & 0.478 & 0.080 \\
\hline$M_{3}$ & $\mathrm{P}_{\text {Impervious }}$ & 2 & -19.795 & 44.018 & 0.499 & 0.079 \\
\hline $\mathrm{M}_{4}$ & Time & 2 & -20.001 & 44.430 & 0.912 & 0.064 \\
\hline \multicolumn{7}{|c|}{ Farmland census sites } \\
\hline$M_{1}$ & $\mathrm{P}_{\text {Trees }}+$ Time & 3 & -16.467 & 39.823 & 0 & 0.176 \\
\hline$M_{0}$ & Null model & 1 & -19.493 & 41.123 & 1.301 & 0.092 \\
\hline $\mathrm{M}_{2}$ & $P_{\text {Grasslands }}$ & 2 & -18.414 & 41.256 & 1.433 & 0.086 \\
\hline$M_{3}$ & $\mathrm{P}_{\text {Trees }}$ & 2 & -18.446 & 41.322 & 1.499 & 0.083 \\
\hline $\mathrm{M}_{4}$ & $P_{\text {Orchards }}$ & 2 & -18.685 & 41.799 & 1.976 & 0.066 \\
\hline
\end{tabular}

Models are ranked according to decreasing statistical support, as indicated by AICc. The 5 best models are shown. Only landscape components that were present in more than two sites were added in the initial model. Percentage of the census site covered by: impervious areas, $\mathrm{P}_{\text {Impervious; }}$ built-up areas, $\mathrm{P}_{\text {Built-up; }}$, herb layer, $\mathrm{P}_{\text {Herb; }}$; shrub and tree layers, $\mathrm{P}_{\text {Trees }} ;$ grasslands, $\mathrm{P}_{\text {Grasslands }}$ orchards, $\mathrm{P}_{\text {Orchards }}$ ivineyards, $\mathrm{P}_{\text {Vineyards; }}$ other types of crops, $\mathrm{P}_{\text {Croplands }}$; or aquatic systems, $\mathrm{P}_{\text {Water }}$ Time since sunrise: Time

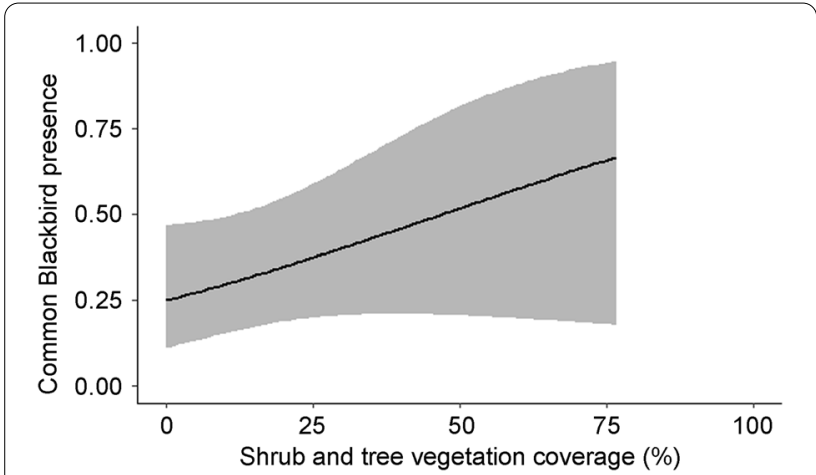

Fig. 3 Predicted Common Blackbird presence response to increasing shrub and tree vegetation coverage in farmland habitat

\section{Discussion}

\section{Common Blackbirds in woodland, farmland and urban habitats}

Overall, our survey documented the presence of Common Blackbirds in woodland, farmland and urban areas. This wide distribution is in accordance with the generalist status of this species and with previous studies, which have reported the presence of blackbirds in rural and urban landscapes (Buckley 1995; Hatchwell et al. 1996). As a generalist species, Common Blackbirds seem to be able to cope with landscape fragmentation and disturbance (Devictor et al. 2008), and they can therefore thrive in anthropogenic urban and rural areas.

Interestingly, and contrary to our expectations, we found that Common Blackbird presence varied between habitats, being significantly higher in woodland and urban habitats than in farmland areas (Cognac vineyard). Such high presence of the species in urban landscapes concurs with the fact that this species has become adapted to the urban environment (Luniak 2004; Evans et al. 2010). Variation in Common Blackbird presence between habitats indicates that the species' presence is either higher in both woodland and urban habitats or reduced in farmland habitats characterized mainly by permanent crops. Regarding the first hypothesis, higher presence in woodland and urban habitats could be explained by two different phenomena. As the original habitat of the species (Luniak 2004), woodlands could be more attractive to Common Blackbirds, therefore explaining the higher presence we observed. In urban habitats, resulting from adaptive mechanisms, bird densities are expected to be higher and home ranges smaller (Snow 1956; Luniak et al. 1997; Luniak 2004; Clergeau et al. 2006). Such adaptations to urbanization could explain the higher presence detected by our census by point counts. Regarding the second hypothesis, the 
significant impoverished presence of Common Blackbirds in vineyards could be explained by rural-specific landscape characteristics and by agricultural practices, resulting for example in low food availability, absence of shelters and nesting sites (Assandri et al. 2017b) or contamination by pesticides, which are massively used in vineyards (Larsen and Noack 2017).

\section{Common Blackbird distribution along fine-scale habitat gradients}

While our results showed that Common Blackbird presence varied between habitats, we did not find any relationship between blackbird presence and fine-scale landscape gradients for any of the three considered habitats. In woodlands, crop and forest gradients $\left(\mathrm{PC}_{1 \mathrm{~W}}\right.$ and $\left.\mathrm{PC}_{2 \mathrm{~W}}\right)$ did not have any influence on Common Blackbird presence. The analysis of each landscape component (taken separately) confirmed that fine-scale landscape variations in woodlands did not modify the suitability of the habitat for Common Blackbirds. This result could be explained by the relative homogeneity of this habitat because all woodland census sites presented a very high percentage of vegetation cover (cover of all layers of vegetation: Mean $\pm \mathrm{SE}, 95.2 \pm 0.7 \%, N=31, \min =83.3 \%$, $\max =100 \%$ ).

Within the urban habitat, urbanization gradient did not explain the variation in presence of Common Blackbirds. In addition, and accordingly, we did not find any influence of each urban landscape component (analysed separately) on blackbird presence. Thus, contrary to our expectation and previous studies on other generalist species (Melles et al. 2003; Sandström et al. 2006; Sol et al. 2014), urbanized sites were not less suitable for Common Blackbirds, at least in our study city. This could be explained by the species' flexibility (Mennechez and Clergeau 2006), the complexity of the effects of urbanization on bird species and communities, and additional variables that we did not measure. Indeed, urbanization is made of a mix of detrimental (e.g. scarcer foraging, sheltering and nesting sites; Mennechez and Clergeau 2006; or human disturbance; Fernández-Juricic et al. 2001) and beneficial components (e.g. reduced predation; Eötvös et al. 2018; prolonged breeding season; Luniak 2004; or increased access to food thanks to bird feeders; Jokimäki and Suhonen 1998). Although we predicted that urban vegetation cover would drive the distribution of Common Blackbirds because of its ecological functions (Davis 1966; Sierro and Arlettaz 2003; Guittet et al. 2011; Assandri et al. 2017b), we did not report any influence of the vegetation $\left(\mathrm{PC}_{1 \mathrm{U}}\right.$ or vegetation cover) on the distribution of urban blackbirds. This surprising result may be linked with the moderate level of urbanization of the studied city, as Niort is a medium-sized city with several green infrastructures and an important green corridor (Beaugeard et al. 2020). Indeed, almost all urban census sites had some vegetation (Mean $\pm \mathrm{SE}, 41.0 \pm 3.2 \%$, $N=31, \min =12.0 \%, \max =68.2 \%)$ and a small patch of vegetation could be sufficient for a small number of this urban-exploiter species to persist in an urbanized landscape (Abs and Bergen 2008).

In farmlands, increasing vineyard cover and decreasing cover of other types of crops $\left(\mathrm{PC}_{1 \mathrm{~F}}\right)$ did not have any significant effect on blackbird presence. Similarly, $\mathrm{PC}_{2 \mathrm{~F}}$ gradient had no effect on blackbird presence, suggesting that farmland census sites with high urban and water coverage were not correlated with a higher presence of the study species. This result suggested that other factors occurring in farmlands may have an impact on the settlement or survival of this bird species in these rural landscapes. As for farmland specialists (Wretenberg et al. 2006), agricultural intensification with its associated habitat fragmentation and destruction, as well as its chemical contamination, is likely to have resulted in a decrease in food availability and sheltering and nesting sites (Hole et al. 2002; Hiron et al. 2013), thus affecting generalist species' settlement and survival. In farmlands, foraging, nesting and sheltering sites are usually provided by vegetation components such as woodlands or hedgerows (Sierro and Arlettaz 2003; Guittet et al. 2011; Assandri et al. 2017b). Interestingly and supporting this hypothesis, we found that a higher proportion of shrubs and trees in farmland census sites had a positive effect on the presence of Common Blackbirds (Table 3). This positive effect of marginal natural habitats on birds in vineyards has been evidenced in other bird species or communities, and especially in species relying on vegetation to hide their nest or to forage (Sierro and Arlettaz 2003; Assandri et al. 2017a; Steel et al. 2017). Although the model including the shrub and tree cover was better supported than the null model by the data, we must remain cautious because the $\triangle$ AIC between these two models was 1.308 only. Additional censuses would therefore be necessary to confirm this result. No other studied habitat component had a significant effect on Common Blackbird presence. Contrary to the studied woodland and urban habitats, the proportion of shrub and tree vegetation cover varied a lot between census sites (Mean $\pm \mathrm{SE}, 13.6 \pm 4.2 \%$, $N=31, \min =0.0 \%, \max =77.2 \%)$. This result suggests that Common Blackbird presence decreases when vegetation becomes too scarce for the species to meet its ecological needs and this effect may be especially apparent in farmlands.

Interestingly, our study demonstrated that habitat and specific habitat characteristics had an effect on the presence/absence of Common Blackbirds, but we could 
not determine the effect of fine-scale landscape components on Common Blackbird abundance (i.e. number of individuals) because of the limited number of detected individuals at each site (two maximum, and in a very limited number of sites). In future studies, it would be interesting to use other census methods (e.g. transects), that allow the assessment of bird abundance (Hanowski et al. 1990; Lee and Marsden 2008). Indeed, the presence of numerous individuals at the same site can be impaired or enhanced by the availability of foraging, sheltering, or nesting sites (Butler 1994; Newton 2007; Cockle et al. 2010), and this may provide useful information to assess the ecological importance of specific habitat components for Common Blackbirds. Moreover, future studies should also look at multiple bird species to allow a better and more global understanding of the impact of key habitat characteristics (urban, farmland, and woodland) on avian biodiversity and on species with various ecological niches and functions.

\section{Conclusions}

Thanks to a census by point count, we documented the presence of Common Blackbirds in three of the main terrestrial habitats of our study area (Western France): woodlands, farmlands dominated by vineyards, and cities. Common Blackbird presence was significantly lower in the studied agricultural system (vineyards) than in woodlands and urban habitats. Although we did not detect any influence of land use gradient on the presence of the species in the three studied habitats (PCA analyses), we found that the cover of shrub and tree vegetation may have a beneficial effect on Common Blackbird presence in the Cognac vineyard. These results confirm that this species is widely distributed in multiple habitats, but it also suggests that its presence could be reduced in altered rural habitats, especially in agricultural systems where hedges and woodland patches are scarce. According to these results, future studies should examine in depth additional farmland habitat characteristics, especially in vineyards, in order to understand how management and conservation policies can enhance not only the presence, but also the abundance of generalist species like the Common Blackbird. A better understanding of these key rural characteristics appears necessary to promote ordinary biodiversity and its associated ecological functions.

\section{Acknowledgements}

We would like to thank the city of Niort for giving us access to urban census sites and for their logistical support. We also thank the National Forest Office (ONF) for allowing us to access studied woodland sites.

\section{Authors' contributions}

$F A, B M$ and $F B$ designed the study. BM and FA conducted data collection. BM, FA and FB performed data analyses. BM and FA wrote the draft manuscript, and FB helped improve the manuscript. All authors read and approved the final manuscript.

\section{Funding}

This research has been funded by the Agence Nationale de la Recherche (ANR project URBASTRESS, ANR-16-CE02-0004-01 to F.A., and ANR project VITIBIRD to F.A.), by the Région Nouvelle-Aquitaine (MULTISTRESS project), by the Agence nationale de sécurité sanitaire de l'alimentation, de l'environnement et du travail (ANSES project BiodiTox \# 2019/1/031) and by the Centre National de la Recherche Scientifique.

\section{Availability of data and materials}

The datasets used and/or analysed during the current study are available from the corresponding author on reasonable request.

\section{Ethics approval and consent to participate}

Not applicable.

\section{Consent for publication \\ Not applicable.}

\section{Competing interests}

The authors declare that they have no competing interests.

\section{Author details}

${ }^{1}$ Centre d'Etudes Biologiques de Chizé, UMR 7372, CNRS - La Rochelle Université, 79360 Villiers en Bois, France. ${ }^{2}$ Environmental and Marine Biology, Åbo Akademi University, 20520 Turku, Finland.

Received: 23 July 2020 Accepted: 14 December 2020

Published online: 05 January 2021

\section{References}

Abs $M$, Bergen $F$. A long term survey of the avifauna in an urban park. In: Marzluff JM, Shulenberger E, Endlicher W, Alberti M, Bradley G, Ryan C, et al., editors. Urban ecology: an international perspective on the interaction between humans and nature. Boston: Springer; 2008. p. 373-6.

Assandri G, Bogliani G, Pedrini P, Brambilla M. Insectivorous birds as 'non-traditional'flagship species in vineyards: applying a neglected conservation paradigm to agricultural systems. Ecol Indic. 2017a;80:275-85.

Assandri G, Giacomazzo M, Brambilla M, Griggio M, Pedrini P. Nest density, nest-site selection, and breeding success of birds in vineyards: management implications for conservation in a highly intensive farming system. Biol Conserv. 2017b;205:23-33.

Baillie J, Hilton-Taylor C, Stuart SN. IUCN red list of threatened species: a global species assessment. Gland: IUCN-The World Conservation Union; 2004.

Barton K. MuMIn: Multi-model inference. R package version 1.43.17. 2020. https://CRAN.R-project.org/package=MuMln.

Beaugeard E, Brischoux F, Angelier F. Green infrastructures and ecological corridors shape avian biodiversity in a small French city. Urban Ecosyst. 2020 https://doi.org/10.1007/s11252-020-01062-7.

Betts MG, Diamond AW, Forbes GJ, Villard M-A, Gunn JS. The importance of spatial autocorrelation, extent and resolution in predicting forest bird occurrence. Ecol Model. 2006;191:197-224.

Bivand RS, Wong DWS. Comparing implementations of global and local indicators of spatial association. TEST. 2018;27:716-48.

Brédif $\mathrm{H}$, Simon L. Ordinary biodiversity, local stakeholders and forest management as a driver for regional sustainable development. J Forest. 2014;04:249-58.

Brouat C, Chevallier H, Meusnier S, Noblecourt T, Rasplus J-Y. Specialization and habitat: spatial and environmental effects on abundance and genetic diversity of forest generalist and specialist Carabus species. Mol Ecol. 2004;13:1815-26. 
Buckley NJ. The new atlas of breeding birds in Britain and Ireland: 1988-1991. In: Gibbons DW, Reid JB, Chapman RA, editors. The Auk. London: T\&AD Poyser; 1995. p. 812-3.

Burnham KP, Anderson DR. Model selection and multi-model inference: a practical information-theoretic approach. 2nd ed. New York: Springer; 2002.

Butler RW. Population regulation of wading Ciconiiform birds. Colon Waterbird. 1994;17:189-99.

Carrara E, Arroyo-Rodríguez V, Vega-Rivera JH, Schondube JE, de Freitas SM, Fahrig L. Impact of landscape composition and configuration on forest specialist and generalist bird species in the fragmented Lacandona rainforest, Mexico. Biol Conserv. 2015;184:117-26.

Clavel J, Julliard R, Devictor V. Worldwide decline of specialist species: toward a global functional homogenization? Front Ecol Environ. 2011;9:222-8.

Clergeau P, Croci S, Jokimäki J, Kaisanlahti-Jokimäki M-L, Dinetti M. Avifauna homogenisation by urbanisation: analysis at different European latitudes. Biol Conserv. 2006;127:336-44.

Cockle KL, Martin K, Drever MC. Supply of tree-holes limits nest density of cavity-nesting birds in primary and logged subtropical Atlantic forest. Biol Conserv. 2010;143:2851-7.

Dabelsteen T. Variation in the response of freeliving Blackbirds Turdus merula to playback of song: I. Effect of continuous stimulation and predictability of the response. ZTierpsychol. 1982;58:311-28.

Dabelsteen T. Variation in the response of freeliving Blackbirds Turdus merula to playback of song: II. Effect of time of day, reproductive status and number of experiments. Z Tierpsychol. 1984;65:215-27.

Dabelsteen T. Interactive playback: a finely tuned response. In: McGregor PK, editor. Playback and studies of animal communication. Boston: Springer; 1992. p. 97-109.

Dabelsteen T, Pedersen SB. Song and information about aggressive responses of blackbirds, Turdus merula: evidence from interactive playback experiments with territory owners. Anim Behav. 1990:40:1158-68.

Davis BNK. Soil animals as vectors of organochlorine insecticides for ground-feeding birds. J Appl Ecol. 1966;3:133-9.

Devictor $V$, Julliard R, Jiguet F. Distribution of specialist and generalist species along spatial gradients of habitat disturbance and fragmentation. Oikos. 2008;117:507-14.

Diehl P, Helb H-W. Radiotelemetric monitoring of heart-rate responses to song playback in blackbirds (Turdus merula). Behav Ecol Sociobiol. 1986;18:213-9

Donald PF, Green RE, Heath MF. Agricultural intensification and the collapse of Europe's farmland bird populations. Proc Biol Sci. 2001;268:25-9.

Ellis EC, Ramankutty N. Putting people in the map: anthropogenic biomes of the world. Front Ecol Environ. 2008;6:439-47.

Eötvös CB, Magura T, Lövei GL. A meta-analysis indicates reduced predation pressure with increasing urbanization. Landsc Urban Plan. 2018;180:54-9

Evans KL, Hatchwell BJ, Parnell M, Gaston KJ. A conceptual framework for the colonisation of urban areas: the blackbird Turdus merula as a case study. Biol Rev. 2010;85:643-67.

Fernández-Juricic E, Jimenez MD, Lucas E. Bird tolerance to human disturbance in urban parks of Madrid (Spain): management implications. In: Marzluff JM, Bowman R, Donnelly R, editors. Avian ecology and conservation in an urbanizing world. Boston: Springer; 2001. p. 259-73.

Foley JA, Defries R, Asner GP, Barford C, Bonan G, Carpenter SR, et al. Global consequences of land use. Science. 2005;309:570-4.

Fritsch C, Coeurdassier M, Faivre B, Baurand P-E, Giraudoux P, van den Brink NW, et al. Influence of landscape composition and diversity on contaminant flux in terrestrial food webs: a case study of trace metal transfer to European blackbirds Turdus merula. Sci Total Environ. 2012:432:275-87.

Futuyma DJ, Moreno G. The evolution of ecological specialization. Annu Rev Ecol Syst. 1988;19:207-33.

Gaston KJ, Fuller RA. Commonness, population depletion and conservation biology. Trends Ecol Evol. 2008;23:14-9.

Guittet M, Sibe V, Gaudin J-C. Les vignobles: de nouveaux réservoirs de biodiversité. Faune sauvage. 2011:9.

Godet L. La «nature ordinaire» dans le monde occidental. L'Espace géographique. 2010;39:295-308.

Gregory RD, Noble DG, Custance J. The state of play of farmland birds: population trends and conservation status of lowland farmland birds in the United Kingdom. Ibis. 2004;146:1-13.
Hanowski JM, Niemi GJ, Blake JG. Statistical perspectives and experimental design when counting birds on line transects. Condor. 1990;92:326-35. Hatchwell BJ, Chamberlain DE, Perrins CM. The demography of Blackbirds Turdus merula in rural habitats: is farmland a sub-optimal habitat? J Appl Ecol. 1996:33:1114.

Hinsley SA, Bellamy PE, Newton I, Sparks TH. Habitat and landscape factors influencing the presence of individual breeding bird species in woodland fragments. J Avian Biol. 1995;26:94-104.

Hiron M, Berg A, Eggers S, Josefsson J, Pärt T. Bird diversity relates to agrienvironment schemes at local and landscape level in intensive farmland. Agr Ecosyst Environ. 2013;176:9-16.

Hobday AJ, Chambers LE, Arnould JPY. Prioritizing climate change adaptation options for iconic marine species. Biodivers Conserv. 2015;24:3449-68.

Hole DG, Whittingham MJ, Bradbury RB, Anderson GQA, Lee PLM, Wilson $J D$, et al. Widespread local house-sparrow extinctions - Agricultural intensification is blamed for the plummeting populations of these birds. Nature. 2002;418:931-2.

Jankowiak Ł, Pietruszewska H, Wysocki D. Weather conditions and breeding season length in blackbird (Turdus merula). Folia Zool. 2014;63:245-50.

Jokimäki J, Suhonen J. Distribution and habitat selection of wintering birds in urban environments. Landsc Urban Plan. 1998;39:253-63.

Julliard R, Jiguet F. Un suivi intégré des populations d'oiseaux communs en France. Alauda. 2002;70:137-47.

Julliard R, Clavel J, Devictor V, Jiguet F, Couvet D. Spatial segregation of specialists and generalists in bird communities. Ecol Lett. 2006;9:1237-44.

Kassen R. The experimental evolution of specialists, generalists, and the maintenance of diversity: experimental evolution in variable environments. J Evol Biol. 2002;15:173-90.

Kubel JE, Yahner RH. Detection probability of Golden-winged Warblers during point counts with and without playback recordings. J Field Ornithol. 2007;78:195-205

Larsen AE, Noack F. Identifying the landscape drivers of agricultural insecticide use leveraging evidence from 100,000 fields. Proc Natl Acad Sci USA. 2017;114:5473-8

Lê S, Josse J, Husson F. FactoMineR: an R package for multivariate analysis. J Stat Softw. 2008:25:1-18.

Lee DC, Marsden SJ. Adjusting count period strategies to improve the accuracy of forest bird abundance estimates from point transect distance sampling surveys: count period strategies for distance sampling surveys. Ibis. 2008;150:315-25.

Lennon JJ, Beale CM, Reid CL, Kent M, Pakeman RJ. Are richness patterns of common and rare species equally well explained by environmental variables? Ecography. 2011;34:529-39.

Luck GW, Smallbone LT. Species diversity and urbanisation: patterns, drivers and implications. In: Gaston KJ, editor. Urban Ecology. Cambridge: Cambridge University Press; 2010. p. 88-119.

Luniak M. Synurbization — adaptation of animal wildlife to urban development. In: Shaw WW, Harris LK, Vandruff L, editors. Proceedings 4th international urban wildlife symposium. Tucson, Arizona: University of Arizona; 2004. p. 50-5.

Luniak M, Kozlowki P, Nowicki W. Magpie Pica pica in Warsaw - abundance, distribution and changes in its population. Acta Orn. 1997;32:77-86.

Mac Nally RC. The relationship between habitat breadth, habitat position, and abundance in forest and woodland birds along a continental gradient. Oikos. 1989:54:44-54

Melles S, Glenn SM, Martin K. Urban bird diversity and landscape complexity: species-environment associations along a multiscale habitat gradient. Conserv Ecol. 2003;7:5.

Mennechez G, Clergeau P. Effect of urbanisation on habitat generalists: starlings not so flexible? Acta Oecol. 2006;30:182-91.

Najmanová L, Adamík P. Effect of climatic change on the duration of the breeding season in three European thrushes. Bird Study. 2009;56:349-56.

Newbold T, Hudson LN, Arnell AP, Contu S, De Palma A, Ferrier S, et al. Has land use pushed terrestrial biodiversity beyond the planetary boundary? A global assessment. Science. 2016;353:288-91.

Newton I. Population limitation in birds: the last 100 years. Br Birds. 2007;100:518-39.

Olden JD. Biotic homogenization: a new research agenda for conservation biogeography. J Biogeogr. 2006;33:2027-39. 
Paquet M, Arlt D, Knape J, Low M, Forslund P, Pärt T. Quantifying the links between land use and population growth rate in a declining farmland bird. Ecol Evol. 2019;9:868-79.

Pithon JA, Beaujouan V, Daniel H, Pain G, Vallet J. Are vineyards important habitats for birds at local or landscape scales? Basic Appl Ecol. 2016;17:240-51.

R Core Team. R: A language and environment for statistical computing. Vienna, Austria: R Foundation for Statistical Computing; 2019.

Ralph CJ, Droege S, Sauer JR. Managing and monitoring birds using point counts: standards and applications. In: Ralph CJ, Droege S, Sauer JR, editors. Monitoring bird populations by point counts. Albany: U.S. Department of Agriculture, Forest Service, Pacific Southwest Research Station; 1995. p. 161-8.

Reif J, Voříšek P, Šṫastny ${ }^{\vee}$ K, Bejček V, Petr J. Population increase of forest birds in the Czech Republic between 1982 and 2003. Bird Study. 2007:54:248-55.

Rotenberry JT, Wiens JA. A synthetic approach to principal component analysis of bird/habitat relationships. In: Capen DE, editor. The use of multivariate statistics in studies of wildlife habitat. Fort-Collins: Rocky Mountain Forest and Range Experiment Station; 1981. p. 197-208.

Sandström UG, Angelstam P, Mikusiński G. Ecological diversity of birds in relation to the structure of urban green space. Landsc Urban Plan. 2006;77:39-53.
Shultz SB, Bradbury RL, Evans KD, Gregory RM, Blackburn T. Brain size and resource specialization predict long-term population trends in British birds. P Roy Soc B-Biol Sci. 2005;272:2305-11.

Sierro A, Arlettaz R. L'avifaune du vignoble en Valais central: évaluation de la diversité à l'aide de transects. Nos Oiseaux. 2003;50:89-100.

Siriwardena GM, Baillie SR, Buckland ST, Fewster RM, Marchant JH, Wilson JD. Trends in the abundance of farmland birds: a quantitative comparison of smoothed Common Birds Census indices. J Appl Ecol. 1998;35:24-43.

Snow DW. Territory in the Blackbird Turdus Merula. Ibis. 1956;98:438-47.

Sol D, González-Lagos C, Moreira D, Maspons J, Lapiedra O. Urbanisation tolerance and the loss of avian diversity. Ecol Lett. 2014;17:942-50.

Stanton RL, Morrissey CA, Clark RG. Analysis of trends and agricultural drivers of farmland bird declines in North America: a review. Agr Ecosyst Environ. 2018:254:244-54

Steel ZL, Steel AE, Williams JN, Viers JH, Marquet PA, Barbosa O. Patterns of bird diversity and habitat use in mixed vineyard-matorral landscapes of Central Chile. Ecol Indic. 2017;73:345-57.

Wretenberg J, Lindström Å, Svensson S, Thierfelder T, Pärt T. Population trends of farmland birds in Sweden and England: similar trends but different patterns of agricultural intensification. J Appl Ecol. 2006;43:1110-20.
Ready to submit your research? Choose BMC and benefit from:

- fast, convenient online submission

- thorough peer review by experienced researchers in your field

- rapid publication on acceptance

- support for research data, including large and complex data types

- gold Open Access which fosters wider collaboration and increased citations

- maximum visibility for your research: over 100M website views per year

At BMC, research is always in progress.

Learn more biomedcentral.com/submissions 